\title{
Chapter 4: Pregnancy and the unborn child
}

\section{Jenny Hall (wordage 5293)}

Human pregnancy is a powerful and strange time. A human being (or more than one) is developing inside a human being. It is a place of transformation for both the woman and the unborn baby. It is a place, too, of the transformation ultimately into a family, with a change in community and society. The International Confederation of Midwives (ICM 2014) recognises this 'profound experience' that brings 'meaning to the woman, her family and the community' within their philosophy. The aim of this chapter is to focus attention onto the unborn child. As a long-term midwife and mother my consideration of the status of the unborn baby as a human being has evolved, including their spiritual nature within the context of a holistic approach to healthcare.

\section{A mother's story}

What does it feel like, being pregnant? I knew. I knew as, I felt different. Not just physical things. This was before the 'missing the period' thing, before the strange metallic taste in my mouth that put me off drinking tea. I knew before the feeling nauseous in the mornings and slightly light headed in the evenings. I knew before I had desperate cravings to eat certain foods, such as yoghurt, and very spicy curry, and celery. I knew before the urgency to get to the toilet to empty my bladder. I knew before the stretching of my skin over my lower abdomen. I knew that there was a person inside me. As the weeks moved on that person would become more real, as she moved and shifted in response to the daily moments of my life. Eating meals would provide a variety of responses. Sitting and lying down would be the times of greatest movements and connections between us: they were the times when I was most aware and wanting to connect, sometimes communicating without words, sometimes talking to her. Music playing would either sooth or encourage movements. The effect of this was noted following birth when the music of a favourite soap I had watched during pregnancy would quiet a fractious baby. She is a person now and was a person then inside me. Coming to birth, and shifting from the world of the womb, to the one outside it, we recognised each other, bonded from the relationship we had already developed over the nine months previously. We had some shared genes and a shared experience of motherhood. We still have a shared humanity.

The story above is my story; my story that I went through five times. I have often reflected if the experience of 'knowing' that I had was because I was a midwife and therefore had 
developed a depth of 'consciousness' about my bodily functions more than others. However, my story is also related by other women (Torngren 2012, Hallett 2002, Stockley 1986, Verny $\&$ Kelly 1982). Stories are told here of 'knowing' the 'spirit or soul' of the baby either waiting to enter the body at or before conception; experiencing feelings physically of the presence of the 'spirit' entering the woman; connecting and communicating with the baby while in the womb; and, also, feeling the presence of the 'spirit' of the baby leaving the woman prior to pregnancy loss.

Developing understanding of the mother-baby dyad is complex. The presence of another being alive inside the mother is referred to as a 'mysterious union' (Bergum 1989, 53). In personhood terms a woman can exist without a baby. A woman becomes a mother through the existence of the baby, whether it lives or it does not survive. The baby, in pregnancy, however, is not able to exist in the early weeks or months without the woman/mother host. Though there is 'creation' of a potential person in methods outside the womb for reproductive implantation such as IVF, there is yet to be developments that enable a baby to 'grow' without the mother. The point where a baby is able to 'exist' without a mother is the point of viability. This is week of life is different in different countries. In the UK this time according to law is at 24 weeks gestation. However, improved care at birth means that more babies having been surviving at earlier times. In 2006, 491 babies were born alive between 22 and 23 weeks (Costeloe et al 2012). Though there have been political moves in the past in the UK to reduce the legal week of viability to 20 weeks, the statistical survival rates are very poor prior to 23 weeks, with 15\% survival at 23 weeks and 55\% at 24 weeks (Tommy's undated). Over the years in the UK I have seen this point drop in weeks as care outside the womb for preterm babies has improved. This point of viability is also legally and ethically different in different countries and societies. Yet there is agreement that the best place, if possible, is for the baby to remain in the host mothers' womb for as long as possible to promote the wellbeing of the baby unless there is risk to the health of the mother (RCOG 2014). This indicates that the mother and baby are inextricably linked.

As indicated in the introduction, I am coming to this writing with a background in midwifery practice that has been grounded in the principles of 'holistic' and 'person-centred care'. According to Greenstreet $(2006,25)$ holistic care is referred to as 'multi-dimensional' and includes 'physical, psychological, spiritual and social aspects' (Greenstreet 2006,25). The integration of whole person and 'person-centred care' is regarded as 'spiritual care' (Clarke 
2013). Internationally such principles also lie in the philosophy of midwifery care which states:

Midwifery care is holistic and continuous in nature, grounded in an understanding of the social, emotional, cultural, spiritual, psychological and physical experiences of women.

(ICM 2014,2).

Though there has been considerable discussion and research around the other aspects of midwifery care identified here, spirituality remains a feature that is ignored. Avoiding the topic, and the aspects of care required, means that women and their babies are not receiving complete, whole-person care.

\section{The soul of the unborn}

Defining spirituality has provided challenge to many researchers, and this book illustrates the complexity. Recent discussion recognises the spiritual nature of all people, and that it is an 'innate human characteristic as essential to the wholeness of being as intellectual, physical and emotional attributes' (de Souza \& Watson 2016,346). Analysis of healthcare research papers from 2002-2013 yielded the conceptual definition of spirituality as:

a way of being in the world in which a person feels a sense of connectedness to self, others, and/or a higher power or nature; a sense of meaning in life; and transcendence beyond self, everyday living, and suffering

(Weathers et al 2016,96).

Such a definition is applicable in the maternal sense where women experience a depth of connectedness to their unborn babies, as I illustrated in the above story, and find a sense of meaning and purpose through the progress of pregnancy as well as the depth of meanings and transcendence that can occur during the process of labour. If we are to understand the 'innate human characteristic' of the spiritual nature of the child in the womb, then we are referring to the 'spirit' or the 'soul' that is inherent.

In an earlier paper, I discussed the roots of the words 'soul' and 'spirit' (Hall 2006) and highlighted they are from different sources. In humanistic contexts the term 'soul' is rarely used as it is more usually associated with religion. Cobb \& Robshaw (1998) indicate that the word 'soul' is associated to an inward depth, self-consciousness and wholeness, while 'spirit' 
is expressed outwardly in relation to expansiveness, consciousness of a God or other being and holiness. Authors write of the centrality of the soul and spirit to the human being:

the sphere of our being that is whole and complete and wherein we are most authentically our Self

(Burkhardt \& Nagai-Jacobson 2002,10).

For the unborn baby, who has consciousness and memory and communicates with the mother (Hepper 1996, Mampe et al 2009 ), it would be logical to consider this human being as a person with a soul.

The question when this baby has a soul in the context of when life begins, is debated intensively in religious and secular terms (Hall 2006). The term 'ensoulment' is used to describe this point when the soul 'enters' the person. The recognition of the beginnings of life and 'personhood' of the baby is different according to moral, ethical and legal standpoints (Shaw 2014). The standpoints have also been evolved over history through the impact of our understandings of the physical development of the pregnancy and the child, as well as the values in society. The ancient Greek philosophers Hippocrates, Plato and Aristotle began work on understanding the physical development of the embryo, and recognised the concept of the 'soul' (Jones 2004). Early writers from a Christian belief perspective, including Basil the Great, St. Augustine and Thomas Aquinas, debated the principles and did not agree over the timing of ensoulment (Jones 2004). In the Jewish religion ethics in medicine is still impacted by the physician and philosopher Moses Maimonides who wrote in the twelfth century about placing women's needs above those of the unborn (Dunn 1998). The Jewish and Christian discussion is based on the ancient Hebrew Scriptures where beliefs lie of conception as being the point where a pre-existing soul enters the unborn and God is then responsible for 'breathing in the spirit' and the subsequent physical development of the unborn. Within Islamic belief there remains considerable debate as to whether ensoulment is at the moment of conception or at the time of 40 days (Ghaly 2012). The suggestion from the debate is there are three stages of the start of life: conception, gaining 'dignity' at implantation (ihtiram) and then achieves sanctity at the point of breathing the soul at 40 days ( hurma). Table 1 illustrates some of the differing viewpoints across some religions.

In some religious beliefs the presence of the soul of the unborn is a result of reincarnation of another who has lived before. For example, in Hindu belief life is a cycle of birth, death and 
then rebirth with the unborn choosing the family they are born into due to the deeds they have achieved in a previous life (Gatred et al 2004, Jayaram undated). Another example is the view of the indigenous peoples of Australia where spirituality is embedded in the significance of the land and where ancestors and 'spirit children' reside. Women receive the pregnancy from the spirits and, at around five months pregnant, when she feels the baby move she will take note of the place where she first felt this as this place will then be significant to that child (Mayra 2012, Carman \& Carman 2013). Such beliefs have been compounded further where the receipt of regression hypnosis has appeared to return a person to their previous life or to the womb (Verny \& Kelly 1981). Recognition of these issues has resulted in an extensive focus through more mystical and so-called 'new age' beliefs to 'communicate' with the unborn spirit (e.g. Hallett 2002, Carman \& Carman 2013).

In the $21^{\text {st }}$ century we are now able to 'look inside' the womb through ultrasound and other visualisation techniques that provides the parents-to-be a window into the person who is their child. These technological advances have led to fundamental debates within religious denominations(Barnhart 1998, Eisenburg 2004, Athar undated). Women who have religious belief will be influenced by the discussions but it should not be assumed that her beliefs match the doctrine. What is evident is that such techniques may now be having an impact on the parents as they are recognising the 'personhood' of the baby much earlier (Ji et al 2005). In a Swedish study asking women before an ultrasound what their feelings were about the examination they talked about meeting the baby and wanting to assess their personality as Gun describes,

...it's kind of getting to see something about how ...he or she looks like, or sort of getting a hold of the character...

(Molander et al 2010, 21)

Technology has thus found a way of introducing the baby as a person to their parents long before the moment of birth.

\section{Women's beliefs}

For a woman (and her partner), the personhood of the baby is powerfully linked with her beliefs of when life is thought to begin. These beliefs will have impacted on her reproductive choices relating to contraception, termination of pregnancy and screening tests offered during the pregnancy (Hall 2002), her choices for her health behaviours in pregnancy (Heidari et al 
2014a \& b, Jesse \& Reed 2004 ) as well as her choice of place of birth and relief for pain in labour (Klassen 2001). The range of beliefs of the personhood of the unborn extend from the moment of conception to when the baby is born. In addition, the values placed on their experience of pregnancy and birth may be intense where they see it is a something that is sacred and holy (e.g. Hebblethwaite 1984, Klassen 2001, Wallas LaChance 1991, Gaskin 2002, Crowther 2013).

Stoyles (2015:93) writes that:

Relational accounts of fetal value allow that pregnancies have whatever meaning and value they are given by the pregnant woman. Thus, relational accounts allow that pregnancy can have little or no positive value and also that pregnancy can have great value

The indication here is the importance of the woman's accounts of her beliefs in the value of the unborn to her. The same paper discusses the views of Lindemann (Stoyles 2015, 94) that the value of the foetus/baby is established by the fact that it has the potential of becoming something of 'moral value'. In addition, the woman 'calls a foetus into personhood' through her behaviours. This implies that, in my own story, as I was so aware of the early 'personhood' of the baby inside me that I saw the baby as a human being, rather than a bunch of cells evolving inside me. Lindemann continues that women/mothers act as though the unborn is already a child by 'connecting' through singing and talking and preparing a physical space for the baby by preparing a nursery and buying equipment that is required. As discussed previously the connections between the mother/baby dyad may begin at any time during pregnancy (e.g. RCM 2012, Torngren 2012, Hallett 2002, Hebblethwaite 1984). However, it is not clear whether this connection is an active choice that women make as an acceptance of the changes taking place in their body or whether it is an internal prompting that makes this connection occur. Suggestions have been made that specific dreams the woman experiences during pregnancy are forms of communication from the unborn (Verny \& Kelly 1982, Carman \& Carman 2013 ). However, it is evident that some women would find such communication with their baby more difficult, especially if the pregnancy has not been wanted/expected or if they have previously experienced infertility or pregnancy loss. There is a reluctance to 'connect' and 'guard' themselves through fear of the same occurring again (Dann 2014, Cote-Arsenault 2007, Brockington et al 2006, Lamb 2002, McGeary 
1994). Women may therefore actively choose not to connect with the pregnancy until the 'threat' of the loss has disappeared.

Complexity also arises with the consideration of termination of pregnancy in society as a maternal choice or as offered for a known concern about the wellbeing of the woman or her unborn baby. In the initial scenario, the woman may choose to actively disconnect from the unborn baby. Her beliefs about the personhood of the unborn will have been influenced by her societal background as well as any religious belief she may have, as discussed previously, and this will impact on her subsequent decision about continuing a pregnancy. Evidence points to the necessity of appropriate counselling prior to termination to prevent psychological sequelae, that ensures the woman has made the choice without coercion from others ( Dresner \& Kurzman 2008, Lipp 2009 ). These women may return to the maternity services in subsequent pregnancies and experience emotional responses as they reconcile the decisions they have previously made with the feelings for the unborn inside them (Hall 1990). For those women who are subsequently offered termination for a known abnormality of the foetus she may have already reached a place of acceptance and communication with the unborn and the decision making will therefore be more complex. There are documented stories of women who choose to continue with the pregnancy, despite diagnosis of serious life-limiting conditions. In both scenarios maternity carers, partners, other family members and friends need to be supportive and aware of the challenging decisions that the women have made.

The discussion here highlights the complexity of recognising the 'personhood' of the unborn in society where there is acceptance of termination in some quarters, yet not in others. Complex debates are taking place in religious contexts that highlight how the principles of the personhood of the unborn 'fits' within religious societies ( eg Tsomo 1998, Jayaram undated). In respect of the understandings of women of the personhood of the unborn debates should continue of these topics in order to balance the views so that women are empowered to make appropriate choices for themselves.

\section{Spiritual nurture of the unborn}

Carolyn Hastie (2008) has written profoundly of the womb itself as a place for spiritual nurture and meaning. She highlights that the wholeness of the woman and a place of reduced stress and anxiety during pregnancy provides the optimum environment for the baby to grow into wholeness. Evidence is growing of the development of physical illness in later life that 
has its origins in the womb (Ekbom et al. 1990, Lashner et al. 1993, Ekbom et al. 1996, Wakschlag et al. 2002). Health promotion is being used to promote the health and wellbeing of the woman in order to impact on the health of the child. For example, reduction of smoking in pregnancy and aims to reduce excessive weight gain are being targeted to improve the long-term health of the baby.

In addition emotional disorders in children have been related to incidents in the womb (Hastie 2008, Verny \& Kelly 1982 ). The holistic intertwining of body-mind-spirit (the hyphens are used here in order to illustrate the interconnectedness) would mean any physical or emotional damage could also have spiritual impact. The women in Heidari et al's (2014) studies who had a religious belief and faith recognised the sacred nature of the maternal responsibility to keep healthy for the sake of the unborn baby's spiritual wellbeing. They would control their diet, who they spent time with in pregnancy and would aim to avoid stressful situations or challenging environments.

Our increasing knowledge of the impact of emotions, health behaviours and stressful situations on the unborn baby's genes increases the need for us to take more seriously mother's needs during pregnancy (Odom and Taylor 2010).

\section{Implications for care in the antenatal period}

The discussions in the chapter will have raised questions for the individual reader. Healthcare practitioners are also human beings with cultural and societal upbringing that will have impact on their beliefs around the start of life. I have raised in a previous paper how these beliefs should be suspended in order to meet the needs and appropriately care for the woman. This may be a challenge where the values women hold are outside the usual expectations of the pathways of care for that society. Maternity carers may be thrown into dilemma as they attempt to support women through their choices and being torn by what they view is the 'right' approach to care. The move to more medical approaches to pregnancy has fragmented the holistic perspective and pushed us into realms where the woman is viewed as a vessel who carries the baby as a passenger. Ethical and moral questions arise of who has the greatest value: the value of the woman or the baby and these questions may only be answered through reverting to the law.

Societal moves have also been toward women making choices to defer having babies until later in their life due to work commitments or later relationships. As a result, there is an increase in artificial reproductive therapies to create babies, as some women may have 
reduced fertility. Questions then arise of the place and values of the unborn in this situation where there may be a sense of creating a 'commodity' potentially as a provision of 'status' for the mother. Balancing the needs and human rights and respect for the woman and her baby are complex issues that require continuing ethical debate.

The recognition of the spiritual value and needs of the unborn leads to questioning of meeting those needs during pregnancy and beyond. In some cultures, there is respect of the unborn as a 'human and deserves our respect as a symbol of future human life' (ESHRE Task force on Ethics and Law 2001). Ethical discussions should therefore continue surrounding any developments of reproductive interventions and how this will impact on future generations (Odent 2002). Women should be able to make choices with knowledge of the potential impact on the wellbeing of herself and of her unborn baby. However, as Carolyn Hastie (2008) has highlighted, there is also a need to prevent anxiety and stress that may be raised due to introducing these topics.

Childbirth is respected and valued in different ways in many cultures (e.g. Kitzinger 2000). It has been highlighted in this chapter that there are differences in cultural and religious beliefs and faith of the parents that impact on their actions, decisions and values. Care during pregnancy therefore should primarily be individualised to a woman's needs and expectations. Encouraging a woman to talk about her beliefs, and understanding of the unborn will help her to gain an understanding and also to encourage development of relationship. A recent study has demonstrated that an unborn baby will respond to the mother's voice or even to her touching her abdomen (Marx and Nagy 2015). When I read this paper, I was reminded how so many pregnant women do touch and stroke their bodies as they see it change and how, perhaps unknowingly, this is receiving a response form their unborn. Intuitive and responsive behaviours toward their unborn baby should be encouraged to enable greater connection.

\section{Implications for care during birth}

Pregnancy and birth are part of an extended continuum. What happens during a pregnancy will then impact on the labour and birth and beyond. Other writers will discuss the spiritual care in labour but there is much to consider around the spiritual needs of the unborn during labour. Increasing technological intervention may be having a long-term effect on future generations (Odent 2002). The increasing use of medicines and interventions to begin labour when the unborn is not ready may have long term effects on the genetics of the baby (Dahlen et al 2013). From a belief in reincarnation principles birth at the 'wrong time' may have an 
impact on the future 'karma' of the individual (Jayaram undated). Further, understanding of memory in relation to the unborn means that lack of care or gentle handling during birth may be 'remembered' in some form (Verny \& Kelly 1982, Hepper 1996, Renggli 2005).

Providing a calm and respectful environment for welcoming a newborn into the birth space will facilitate the relationship to grow between the mother and the baby and prevent trauma that could impact longterm. More needs to be done to enable women to express their faith and practice their cultural beliefs and rituals to welcome the baby in a safe space.

\section{Conclusion}

The aim of this chapter has been to consider the value of the unborn baby and discuss their spirituality in the context of holistic values of mind-body-spirit. Discussion has revealed the unborn child in its personhood, soul and spirit. In exploring the philosophies from a variety of global perspectives I have aimed to encourage further debate. As technology is continually advancing around reproductive technologies the spiritual, ethical and moral values that underpin life should not be ignored. I have aimed to bring forward the voice of women in these discussions who see the importance of the sacred place of pregnancy and childbirth, and the depth of the mother-baby connecting relationship. Despite the increasing worldwide move toward technological controls around birth, women and babies honour this sacred event, and we should do the same.

\section{References}

Athar S. (undated) Islamic Perspective in Medical Ethics. Available at: http://www.islam-

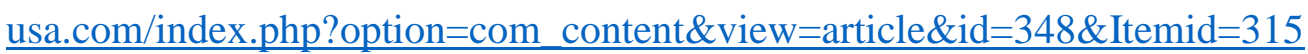

Barnhart M.G. 1998 Buddhism and the morality of abortion. Journal of Buddhist ethics 5, 276-297.

Bergum V. 1989 Woman to Mother: A Transformation. Bergin \& Garvey Pubs. Inc., MA, p. 53.

Brockington, I., Macdonald, E. \& Wainscott, G. 2006 Anxiety, obsessions and morbid preoccupations in pregnancy and the puerperium. Arch Womens Ment Health 9: 253.

Burkhardt M.A. \& Nagai-Jacobson M.G. 2002 Spirituality. Living our connectedness Albany: Delmar. 
Carman Elizabeth M. \& Carman Neil J. 2013 Cosmic Cradle, Revised Edition: Spiritual Dimensions of Life before Birth North Atlantic Books: Berkley

Clarke J., 2013 Spiritual care in everyday nursing practice: A new approach. Basingstoke: Palgrave Macmillan.

Cobb M. \& Robshaw V. 1998 The Spiritual Challenge of Health Care. Churchill Livingstone, Edinburgh, pp. 42-44.

Costeloe K.L., Hennessy E.M., Haider S., Stacey F., Marlow N., Draper E.S. et al. 2012 Short term outcomes after extreme preterm birth in England: comparison of two birth cohorts in 1995 and 2006 (the EPICure studies) BMJ 345 :e7976

Crowther S.2013 Sacred space at the moment of birth Pract Midwife. 16(11):21-3.

Cote-Arsenault D. (2007) Threat appraisal, coping and emotions across pregnancy subsequent to perinatal loss Nurs Res 56(2) 108-16

Dahlen H.G., Kennedy H.P., Anderson C.M., et al. The EPIIC hypothesis: Intrapartum effects on the neonatal epigenome and consequent health outcomes. Medical hypotheses. 2013;80(5):656-662. doi:10.1016/j.mehy.2013.01.017.

Dann L. 2014 Women's experience of pregnancy and early motherhood following repeated IVF treatment: a phenomenological study A thesis submitted in partial fulfilment of the requirements for the degree of Doctor of Health Science available from: http://aut.researchgateway.ac.nz/bitstream/handle/10292/7213/DannL.pdf?sequence=3

Dresner, N., Kurzman, A. 2008 Psychological Aspects of Abortion Glob. libr. women's med.,(ISSN: 1756-2228) 2008; DOI 10.3843/GLOWM.10417

Dunn P. (1998) Maimonides (1135-1204) and his philosophy of medicine. Archives of Disease in Childhood 79, 227F-228F.

Eisenburg D. (2004) Abortion in Jewish Law. Available at: http://www.aish.com/ci/sam/48954946.html

Ekbom A, Adami H., Helmick C.G., Jonzan A., Zack M.M. (1990) Perinatal risk factors for inflammatory bowel disease; a case control study. American Journal of Epidemiology 132, 1111-1119.

Ekbom A., Hsieh C.C., Lipworth L., Wolk A., Ponten J., Adami H.O. \& Trichopoulos D. (1996) Perinatal characteristics in relation to incidence of and mortality from prostate cancer. British Medical Journal 313, 337-341.

ESHRE Task Force on Ethics and Law (2001) The moral status of the pre-implantation embryo. Human Reproduction 16, 1046-1048. 
Gatrad A.R., Ray M., Sheikh A. 2004 Hindu birth customs Archives of Disease in Childhood, 89(12): 1094-1097

Gaskin I.M. (2002) Spiritual Midwifery, 4th edn. Book Publishing Company, TN.

Ghaly M.. 2012 The beginning of human life: Islamic bioethical perspectives Zygon, 47 (1) $175-213$

Greenstreet W. (ed) 2006 Integrating Spirituality in health and social care: Perspectives and practical approaches Oxford, Radcliffe

Hall, Jennifer 2006. Spirituality at the beginning of life Journal of Clinical Nursing

15(7):804-10

Hall, J. (1990). A hard decision... termination of an unwanted pregnancy. Nursing

Times, 86(47), 32-35.

Hallett, . 2002 Stories of the Unborn Soul: the mystery and delight of pre-birth communication Bloomington: iUniverse

Hastie, C. 2008 The spiritual and emotional territory of the unborn and newborn baby in: K Fahy, M Foureur, C Hastie (eds) Birth Territory and Midwifery Guardianship Books for midwives: Oxford

Hebblethwaite, M. (1984) Motherhood and God. Geoffrey Chapman, London.

Heidari T., Ziaei S., Ahmadi F., Mohammadi E. \& Hall J. 2014a Maternal Experiences of Their Unborn Child's Spiritual Care: Patterns of Abstinence in Iran J Holist Nurs. 33(2):14658

Heidari, T., Ziaei S., Ahmadi F., Mohammadi, E. 2014b Powerful Leverages and CounterCurrents in the Unborn Child Spiritual Care: A Qualitative Study. Global Journal of Health Science. 2015;7(1):122-132. doi:10.5539/gjhs.v7n1p122.

Hepper, P.G. (1996) Fetal memory: does it exist? What does it do? Acta Paediatrica Supplement 416, 16-20.

International Confederation of Midwives (ICM) 2014 Philosophy and Model of Midwifery Care [online] Available from :

http://www.internationalmidwives.org/assets/uploads/documents/CoreDocuments/CD2005_0 01\%20V2014\%20ENG\%20Philosophy $\% 20$ and $\% 20$ model $\% 20$ of $\% 20$ midwifery $\% 20$ care.pdf

Jayaram, V. (undated) Hinduism and abortions [online] available from: http://www.hinduwebsite.com/hinduism/h_abortions.asp 
Jesse, D. E., Reed, P. G 2004 Effects of Spirituality and Psychosocial Well-Being on Health Risk Behaviors in Appalachian Pregnant Women J Obstet Gynecol Neonatal Nurs. 33(6):739-47

Ji, E.K., Pretorius, D.H., Newton, R., Uyan, K., Hull, A.D., Hollenbach, K., Nelson, T.R. 2005 Effects of ultrasound on maternal-fetal bonding: a comparison of two- and threedimensional imaging.Ultrasound Obstet Gynecol. 25(5):473-7

Jones, D.A. 2004 The Soul of the Embryo. Continuum, London

Klassen, P.E. 2001 Blessed Events-Religion and Home Birth in America. Princeton University Press, Princeton.

Lamb, E.H. 2002 The Impact of Previous Perinatal Loss on Subsequent Pregnancy and Parenting. The Journal of Perinatal Education. 2002;11(2):33-40.

Lashner B.A., Shaheen, N.J., Hanauer, S.B., Kirschner, B.S. 1993 Passive smoking is associated with an increased risk of developing inflammatory bowel disease in children. American Journal of Gastroenterology 88, 356-359.

Lipp, A. (2009) Termination of pregnancy: a review of psychological effects on women. Nursing Times; 105: 1, 26-29

Mampe, B., Friederici, A.D., Christophe, A. \& Wermke, K. 2009 Newborns' cry melody is shaped by their native language.Current Biology 19, 1994-1997

Marx, V., Nagy, E. 2015 Fetal Behavioural Responses to Maternal Voice and Touch PLOS one [online] available from:http://journals.plos.org/plosone/article?id=10.1371/journal.pone.0129118

Mayra 2012 The Dreaming - Australian Aboriginal peoples

http://partopelomundo.com/blog/2011/12/30/the-dreaming-australian-aborigenes/

McGeary, K. 1994 The influence of guarding on the developing mother-unborn relationship. In Uncertain Motherhood: Negotiating the risks of the childbearing years Field PA \& Marck PB eds. Sage Publishing, London.

Molander, E. Alehagen, S', Berterö, C.M. 2010 Routine ultrasound examination during pregnancy: a world of possibilities Midwifery 26(1):18-26.

Odent, M. 2002 The Farmer and the Obstetrician. Free Association books, London. 
Odom, L.N., Taylor, H.S. 2010 Environmental induction of the fetal epigenome. Expert review of obstetrics \& gynecology. 5(6):657-664.

RCM 2012 Maternal emotional wellbeing and infant development: a good practice guide for midwives

https://www.rcm.org.uk/sites/default/files/Emotional\%20Wellbeing_Guide_WEB.pdf

RCOG 2014 Perinatal Management of Pregnant Women at the Threshold of Infant Viability (The Obstetric Perspective) Availability from:

https://www.rcog.org.uk/globalassets/documents/guidelines/scientific-impact-

papers/sip_41.pdf

Renggli, F. (2005) Healing and Birth. Journal of Prenatal and Perinatal Psychology and Health 19, 303-318.

Shaw, A. 2014 Rituals of infant death: defining life and Islamic personhood Bioethics 28 (2) 84-95

de Souza, M., and Watson, J., 2016 Understandings and Applications of Contemporary Spirituality: Analysing the Voices in M. de Souza, J. Bone, J. Watson (eds.) Spirituality across Disciplines: Research and Practice (pps. 331-348) Springer: Switzerland

Stockley, S. 1986 Psychic and spiritual aspects of pregnancy, birth and life In: Ros Claxton (ed) Birth Matters: issues and alternatives in childbirth Unwin books: London

Stoyles, B.J. 2015 The Value of Pregnancy and the Meaning of Pregnancy Loss Journal of Social Philosophy 46 (1) 91-105

Tommy's (undated) Premature birth statistics [online] available from:

https://www.tommys.org/our-organisation/why-we-exist/premature-birth-statistics

Torngren, P. 2012 Voices from the Womb - Four Mothers Tell About Prebirth communication [online] available from: http://www.parenting-with-love.com/voices-fromthe-womb-prebirth-communication/

Tsomo, Karma Leksh 1998 Prolife, Prochoice: Buddhism and Reproductive Ethics Feminism \& Nonviolence Studies, Fall [online] available from: http://www.fnsa.org/fall98/tsomo.html

Verny, T. \& Kelly, J. 1982 The Secret life of the unborn child. Sphere books, London.

Wallas LaChance, C. 1991 The Way of the Mother: The Lost Journey of the Feminine. Vega, London. 
Wakschlag, L.S., Pickett, K.E., Cook, E., Jr, Benowitz, N.L. \& Leventhal, B.L. (2002)

Maternal smoking during pregnancy and severe antisocial behavior in offspring: a review.

American Journal of Public Health 92, 966-974.

Weathers, E., McCarthy, G., \& Coffey, A. 2016 Concept Analysis of Spirituality: An Evolutionary Approach Nursing Forum 51 (2) 79- 96

Table 1 Religious views of timing of ensoulment

\begin{tabular}{|l|l|}
\hline Religious belief & View of timing of ensoulment \\
\hline Christian & $\begin{array}{l}\text { Depends on denomination: Some at conception, some at implantation } \\
\text { Biblical texts suggest that the fetus may have a spirit }\end{array}$ \\
\hline Judaism & $\begin{array}{l}\text { Suggests a fetus may not be a person until it is born though some have } \\
\text { stated that the fetus a potential person and should be treated with value } \\
\text { because of this. Belief that a person has a perfect soul when born and } \\
\text { the spirit of that fetus was perfect }\end{array}$ \\
\hline Islam & $\begin{array}{l}\text { Ensoulment believed to be either at 120 days (17 weeks), 40 days or } \\
\text { when there is movement (12th week up to 20+ weeks) Though many } \\
\text { believe that life begins at conception. }\end{array}$ \\
\hline Buddhism & $\begin{array}{l}\text { Believe the moment of conception as the beginning of life of a newly } \\
\text { embodied individual }\end{array}$ \\
\hline Hindu & $\begin{array}{l}\text { The soul and body forming the fetus and thought to be joined together } \\
\text { from conception }\end{array}$ \\
\hline Sikhism & $\begin{array}{l}\text { Gost believe life begins at conception } \\
\text { Some believe the spirit of the unborn is present in the house before } \\
\text { conception others believe the spirit enters later in pregnancy }\end{array}$ \\
\hline Paganism &
\end{tabular}

Previously published in Hall J, 2006. Spirituality at the beginning of life Journal of Clinical Nursing 15(7):804-10 Used with permission 